\title{
Criterios y técnicas de intervención en tapia. La restauración de la torre Bofilla de Bétera (Valencia)
}

\author{
Criteria and intervention techniques in rammed earth \\ structures. The restoration of Bofilla tower at Bétera \\ (Valencia) \\ $\underline{\text { C. Mileto }}^{(*)}$, F. Vegas(*), J.M. López ${ }^{(* *)}$
}

\section{RESUMEN}

Este artículo expone una reflexión sobre los diversos criterios y técnicas de intervención en las construcciones de tapia realizadas en España en las últimas décadas, las dificultades intrínsecas de esta delicada operación y las consecuencias que se derivan de cada una de las opciones posibles para la conservación de la autenticidad, la materialidad, las trazas impresas de sus fábricas, etc. Para ello, realiza en primer lugar un breve repaso al abanico de diversas variantes de tapia existentes en la península que plantean problemáticas diversas de restauración a tenor de su enjundia constructiva.

En segundo lugar, presenta tres grandes grupos de intervenciones, a saber, las intervenciones con recuperación de volúmenes, la restauración con sustitución de superficies y las actuaciones de conservación y protección de las fábricas. Estos tres tipos de intervenciones se ilustran con ejemplos de las últimas tres décadas en el territorio español, donde se describen sucintamente tanto los criterios y las técnicas empleadas como los resultados obtenidos tras el proceso de intervención.

Por último, y como conclusión del estudio sobre todos estos criterios y técnicas y a la luz de los resultados habidos a lo largo de las últimas décadas, presenta en detalle el estudio previo, los criterios, las técnicas y las modalidades de puesta en obra en la restauración de la torre Bofilla en Bétera (Valencia) realizada por los autores, como posible opción de intervención en estructuras históricas de tapia.

113.103

Palabras clave: tapia, tapial, restauración, criterios, técnicas de intervención.

\section{SUMMARY}

This article presents a reflection on the various criteria and intervention techniques in rammed earth constructions carried out in Spain over the last decades, the intrinsic difficulties of this delicate operation and consequences resulting from each possible option for conservation of the authenticity, materiality, imprinted traces of its factories, and so on. First of all, it takes place a brief overview to the range of rammed earth variants existing on the Iberian Peninsula, that present various problems for restoration because of their different constructive devices that raise specific issues when it comes to restore them.

Secondly, it introduces three great groups of interventions, ie, interventions recovering lost volumes, surfaces substitution restoration and conservation and protection actions of the historic fabrics. These three types of interventions are explained through examples done during the last three decades in Spain, where a briefly description both of the applied criteria and employed techniques and the results obtained after the intervention process.

Finally, as a conclusion of the study on all these criteria and techniques and taking into account the results collected over recent decades, the restoration of Bofilla tower at Bétera (Valencia), done by the authors of this paper, is displayed with its study, analysis, criteria, techniques and on site implementation, as a possible option for the historic rammed earth structures restoration.
Keywords: rammed earth, formwork, restoration, criteria, techniques.

\footnotetext{
(*) Universitat Politècnica de Valencia, Valencia (España)

(*) Universidad de Málaga, Málaga (España)

Persona de contacto/Corresponding author: cami2@cpa.upv.es (C.Mileto)
}

Fecha de recepción: 22-02-10 Fecha de aceptación: 04-05-10 
1. Tapiales (1), agujas (2), costales (3), montaje del tapial (4) pisón (5). J. de Villanueva. Arte de Albañilería, 1827. Lámina III, capítulo 5

2. Tapia de tierra. Marruecos (fotografía: J.M. López Osorio)
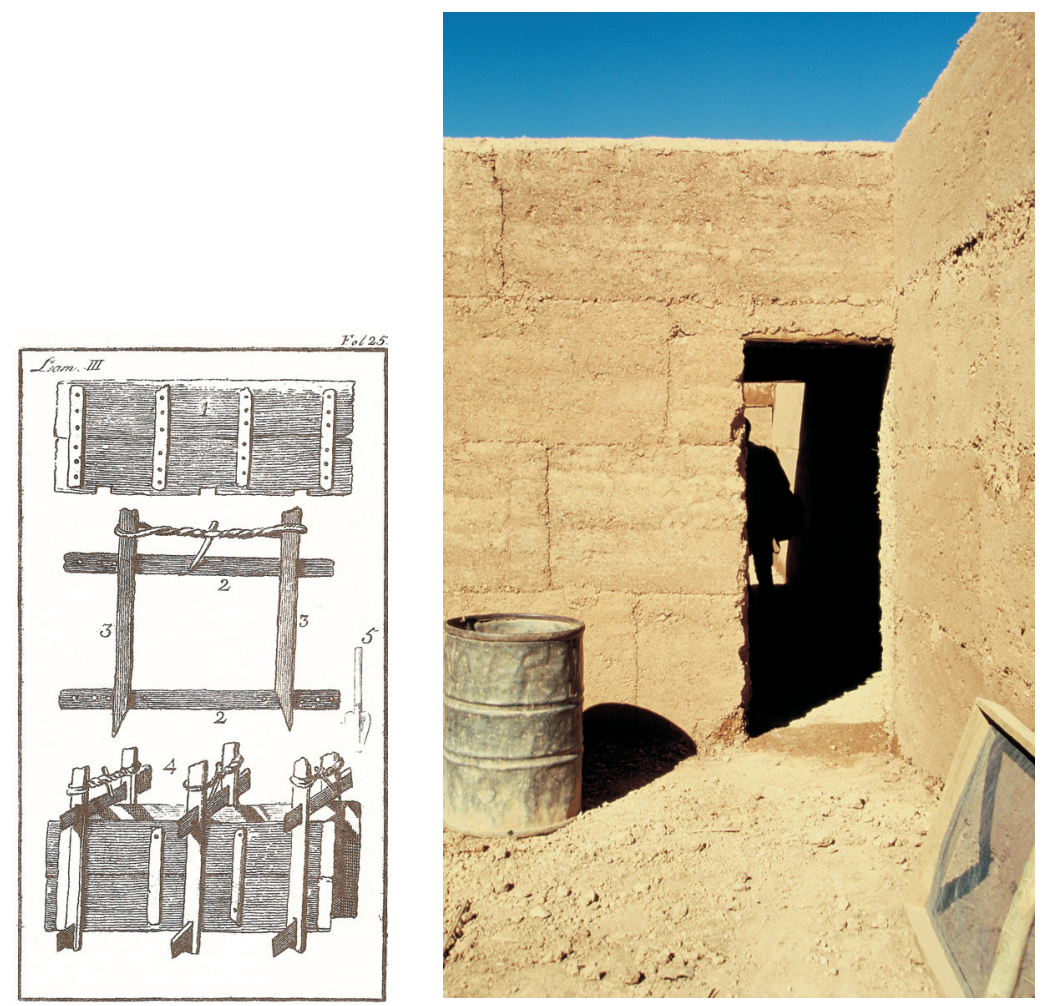

\section{LA TÉCNICA CONSTRUCTIVA DEL TAPIAL}

La península ibérica constituye el área geográfica europea que reúne la mayor concentración de arquitectura construida en tapia (1). Desde hace algún tiempo se viene estudiando a fondo este tipo de técnica constructiva y sus variantes (tapia de tierra, tapia de hormigón de cal, tapia calicostrada, tapia valenciana, tapia encadenada, tapia con brencas, etc.).

El camino realizado en la intervención en edificios históricos de tapia también posee ya cierto recorrido. Desde la década de 1980 se ha intervenido cada vez más en edificios de tapia, tanto monumentales como populares o vernáculos. Diversas han sido las intervenciones realizadas en este patrimonio histórico tanto de reconstrucción, conservación, reparación, sustitución, consolidación estructural, etc. Diversos han sido también los criterios empleados: conservación de la autenticidad material, mínima intervención, compatibilidad, recuperación formal y volúmetrica, recuperación tipológica, recuperación de la técnica constructiva, actualidad expresiva, etc. A los diversos criterios empleados corresponden diferentes técnicas, materiales o acciones de intervención. Diversos han sido también los resultados derivados de las intervenciones tanto a nivel de impacto sobre el edificio, como de durabilidad técnica y material.

La técnica constructiva del tapial resulta habitualmente vinculada al extenso y variado campo de la arquitectura de tierra. Sin embargo, la tapia y la tierra no siempre poseen una relación directa ya que no en todos los casos la tierra constituye el único material utilizado en la construcción de la tapia. Es así que, aunque la tapia más extendida y característica sea la tapia de tierra, se pueden encontrar tapias encadenadas con ladrillo o piedra, tapias de hormigón, tapias calicastradas, tapias valencianas o tapias de brencas.

Conviene matizar también la diferencia, tal vez olvidada, entre el tapial y la tapia. El tapial es una técnica o sistema constructivo mediante el cual se levantan muros o paredes utilizando dos tableros paralelos o encofrados que le sirven de horma y en los que se utiliza el recurso del apisonado como medio de estabilización y consolidación de la masa (2). Los tapiales, por extensión, son también los encofrados o tableros necesarios para la ejecución del muro. El término tapia, expresión más rigurosa y frecuentemente utilizada en las fuentes documentales y tratados de construcción (3), responde con carácter general a la pared, estructura, muro o módulo que se realiza con esta técnica. La palabra tapia posee en la península ibérica un origen etimológico con referencia directa a la tierra, sin embargo la aplicación del término en su sentido estrictamente constructivo resulta más amplio y no se limita a este material.

La diversidad y singularidad de los sistemas constructivos de tapia supone un campo de amplia difusión temporal y geográfica con un repertorio variado de técnicas y materiales. Resulta difícil, por tanto, abarcar en su totalidad la diversidad tipológica y mucho más, si cabe, establecer terminologías o definiciones precisas. No obstante, en este apartado, se intentará realizar un breve análisis de los sistemas constructivos de la tapia, tratando de establecer unos principios básicos.

El procedimiento tradicional para la construcción de una tapia consiste en instalar un par de encofrados o tapiales, normalmente de madera, apoyados sobre unos travesaños horizontales denominados agujas y sujetos mediante sistemas variables de costales, codales, puntales, etc. (Figura 1). El muro se construye merced a la repetición modular en horizontal y en vertical de tapias con alturas que oscilan entre 60 y $90 \mathrm{~cm}$. En una tapia de tierra (Figura 2), el material que rellena el interior de los tapiales es una masa de tierra cruda mezclada habitualmente con grava o 

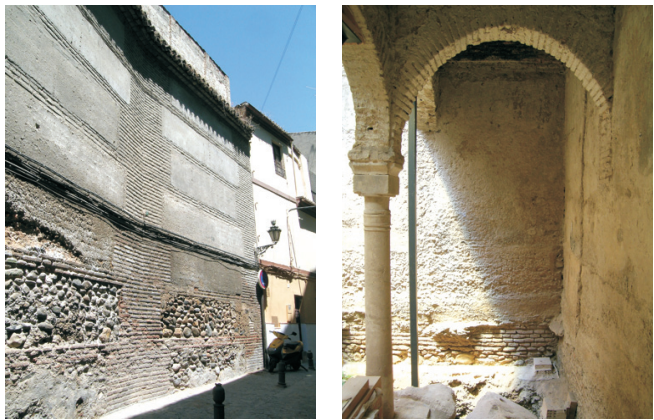

arena que, vertida y apisonada por tongadas, completa la altura deseada. En este caso el elemento que aglutina y aporta resistencia al muro es la arcilla, aunque en ocasiones pueden añadirse pequeñas cantidades de cal para estabilizar la masa. La construcción de la tapia de tierra presenta un modelo sencillo y ecológico que no exige la utilización de materiales elaborados, ya que la tierra utilizada para construir la tapia procede del mismo lugar donde se realiza la construcción. Sin embargo, un muro de tierra resulta especialmente expuesto, bien a la acción erosiva del agua que afecta a los paramentos bien a la procedente del terreno. El proverbio de Gales "Giv un a gude 'at an' a gude 'pair o' byutes an ee'll lyuke arter isself"(4) ("Dale un buen sombrero y un buen par de botas y se cuidará solo") expresa directamente y de forma muy gráfica esta debilidad y a la vez el potencial de las fábricas de tierra.

La vulnerabilidad de la tapia de tierra cruda se intentó solventar a través de una serie de mejoras técnicas. La construcción de la tapia sobre un zócalo de piedra o ladrillo y el revestimiento exterior de sus paramentos con mortero de cal constituyen medidas adecuadas para la protección de la fábrica. Sin embargo, existen otras elaboraciones del sistema constructivo que persiguen una mayor durabilidad, como es el caso de la fábrica mixta (con diversos nombres según los autores: tapia encadenada, tapia verdugada, tapia de fraga, tapia de tierra y machones, 5-6) formada por machones verticales de ladrillo o piedra y verdugadas horizontales de ladrillo o mampuestos que confinan cajones interiores de tapia (Figura 3). Los cajones se rellenan con tapias de tierra en los niveles superiores y con tapia de mampostería en los niveles en contacto con el terreno para brindar mayor estabilidad estructural y mejorar la resistencia frente a la acción de las escorrentías superficiales y la ascensión capilar de la humedad.

Evidentemente mucho más resistente es la fábrica de tapia de hormigón de cal (Figura 4), una variante de la tapia donde el muro está constituido por una argamasa de cal y grava de diferente granulometría (7). Se trata
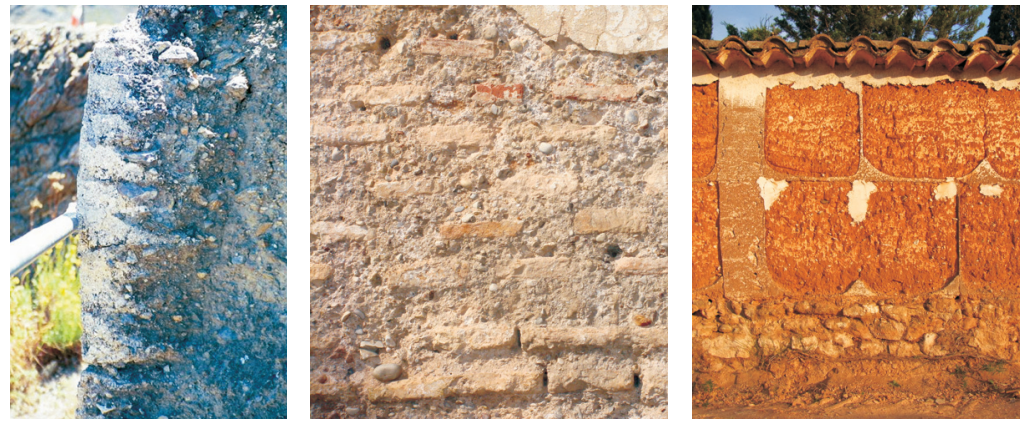

de un sistema constructivo frecuentemente utilizado en la construcción de los baños árabes, aljibes y albercas, es decir, su uso se circunscribe a las estructuras hidráulicas con presencia directa de agua o con estancias sometidas a alto contenido en humedad. La tapia de hormigón de cal enlaza directamente con el opus caementicium de tradición romana, donde el relleno del interior del muro está formado por una argamasa de grava, arena y cal. En ensayos realizados en hormigones islámicos del baño árabe de Hernando de Zafra en Granada, se han encontrado dosificaciones en cal de hasta un $30 \%$ y altas resistencias a compresión que alcanzan valores hasta $234 \mathrm{Kp} / \mathrm{cm}^{2}$ (8). No cabe duda que la tapia de hormigón presenta óptimos resultados en cuanto a su resistencia a las cargas gravitatorias, empujes horizontales y protección superficial de los paramentos, al punto que sería una óptima opción para la construcción de murallas de una ciudad, si no fuera porque representaría un consumo de recursos excesivos en casos de gran envergadura.

La tapia calicastrada (Figura 5) surge como respuesta a esta circunstancia y, aunque también es frecuente encontrarla en la arquitectura doméstica, resulta un modelo constructivo especialmente indicado para la construcción de lienzos y torres de muralla, ya que permite levantar una tapia con masa interior de tierra protegida con mortero o costra de cal en su cara exterior en una operación simultánea. El sistema consiste en proyectar por el interior de los tapiales o encofrados una capa de mortero de cal antes de proceder al vertido de la tongada de tierra. Esta operación se realiza en bandas horizontales que coincidirán con una o varias tongadas de tierra. Al realizar el apisonado los dos materiales quedan perfectamente adheridos, presentando un característico acuñado que garantiza el perfecto anclaje entre el revestimiento exterior y la masa interior de tierra. La técnica supone un ahorro considerable de cal en la construcción del muro si lo comparamos con una tapia de hormigón, consiguiendo, no obstante, un acabado superficial altamente resistente $y$ una durabilidad muy superior a la tradicional tapia de tierra (9).
3. Tapia mixta con machones $y$ bolos en la parte inferior y tapias calicastradas en la parte superior del muro. Granada (fotografía: J.M. López Osorio)

4. Tapia de hormigón de cal. Baño de Hernando de Zafra, Granada (fotografía: J.M. López Osorio)

Tapia calicastrada. Castillo de la Peza, Granada (fotografía: J.M. López Osorio)

6. Tapia valenciana. Convento del Pilar, Valencia (fotografía: Mileto \& Vegas)

Tapia con brencas. Cementerio de Torrebaja, Valencia (fotografía: Mileto \& Vegas) verdugadas de ladrillo y tapias de 


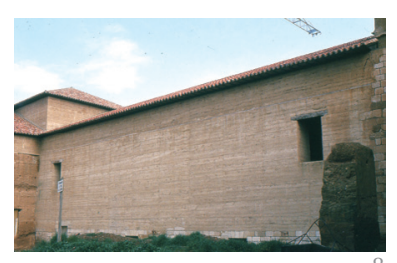

8. Tapias nuevas realizadas en el Toral de los Guzmanes, León (fotografía: E. Algorri)

9. Vista general de la Muralla de Niebla (Huelva) restaurada (fotografía: Mileto \& Vegas)

10. Detalle del encuentro entre las tapias antiguas y las tapias nuevas realizadas en la restauración de la Muralla de Niebla (Huelva) (fotografía: Mileto \& Vegas)
Existen también otras variantes de la técnica constructiva del tapial que persiguen una cierta durabilidad y resistencia a través del refuerzo superficial de la tapia de tierra con otros materiales y por esta razón se denominan también tapias reforzadas (10) o tapias mixtas (7). La primera es la tapia valenciana (Figura 6), ya nombrada así por Fray Lorenzo de San Nicolás en su tratado en 1633 (11), que consiste en una tapia realizada con un paramento externo con ladrillos, normalmente a tizón, colocados al tresbolillo que afloran en la costra de cal (12). La tapia se construye poniendo los ladrillos entestados a la cara interior del tapial y vertiendo y apisonando tongadas de tierra y cal sucesivamente (7). El muro de tapia valenciana acabado se caracteriza por una superficie de mortero de cal ritmada por los ladrillos ligeramente rehundidos (13). En algunos casos en vez de ladrillos se utilizan también mampuestos (7). La segunda variante es la tapia con brencas (Figura 7), una tapia de tierra reforzada con yeso, material más económico que la cal y abundante sobre todo en algunas regiones del interior de España (Aragón, Castilla La Mancha) (14). El
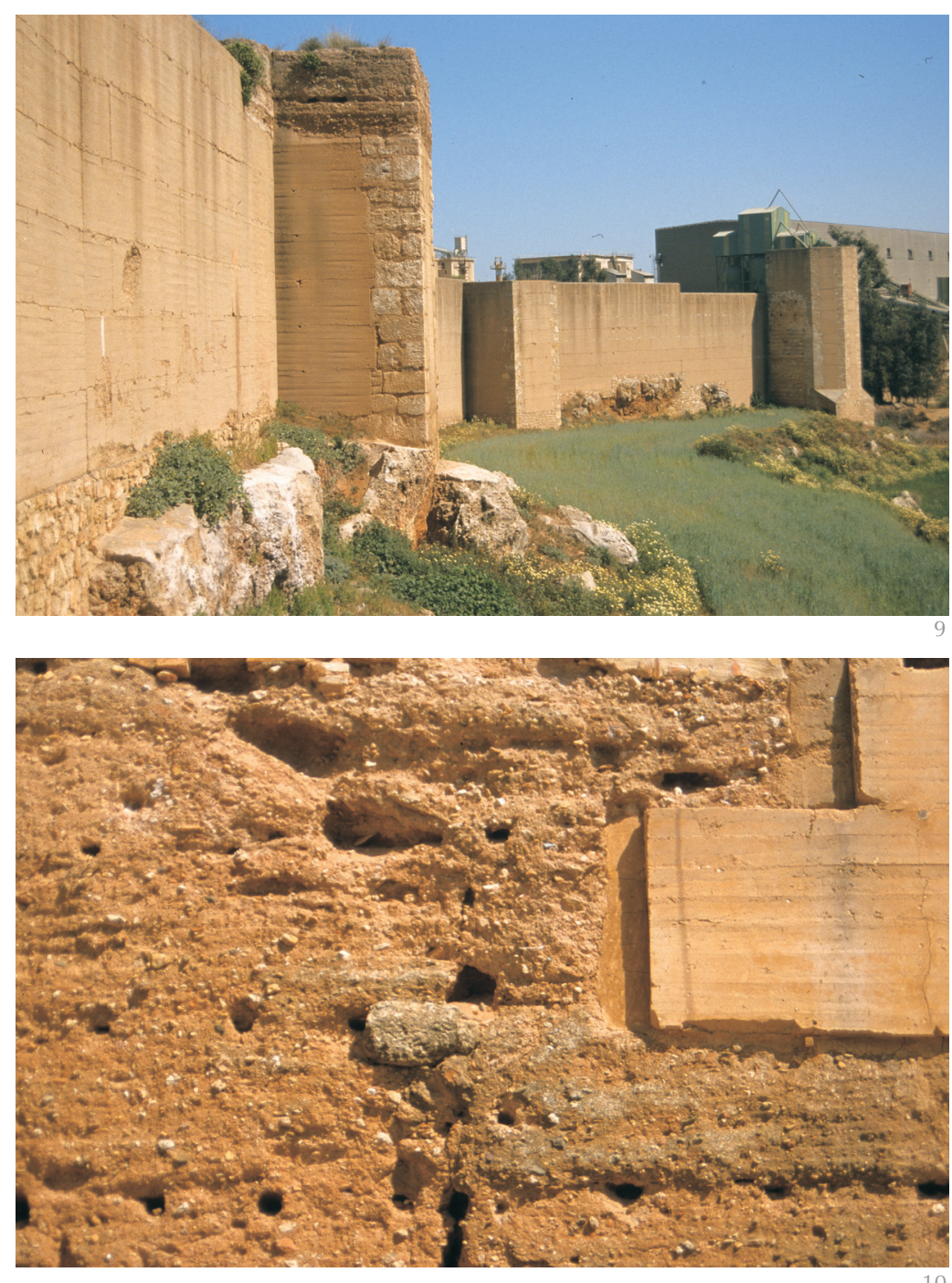

término catalán brenca (10) indica la medialuna más resistente de mortero de yeso que se forma en los extremos de cada tapia derivada del mismo proceso constructivo: cada vez que se monta el tapial se extiende un estrato de yeso, a veces muy abundante, tanto en la superficie inferior como en los dos laterales de contacto con las otras tapias creando una $L$ de yeso redondeada en la esquina del tapial para facilitar el apisonado, que confiere al muro su característico efecto de ondas.

Por concluir esta breve explicación, se debe recordar que consideramos fábrica de tapia cualquier muro construido con la técnica del encofrado, cuyo interior se rellene con mampostería o ladrillo, utilizando para su recibido o retacado morteros de cal o pastas de yeso.

\section{CRITERIOS Y TÉCNICAS DE INTERVENCIÓN EN FÁBRICAS DE TAPIA. UNA REFLEXIÓN PREVIA}

Las intervenciones históricas de reparación llevadas a cabo en las tapias principalmente de torres y lienzos de muralla consistían, en la mayor parte de los casos, en trabajos de recalce o reconstrucción de lienzos, y se realizaban con fábricas mixtas de piedra y ladrillo, ya que su intención no era más que recuperar el carácter funcional y la estabilidad estructural de estas estructuras defensivas. Ejemplos de este tipo de intervenciones las encontramos en los recalces realizados en época cristiana en la Alhambra de Granada o en la Alcazaba de Málaga.

Si exceptuamos algún ejemplo aislado, no fue hasta la segunda mitad del siglo XX cuando las intervenciones en tapias históricas se sometieron a los criterios de la disciplina de la restauración. A efectos de realizar una reflexión sobre las posibles opciones de intervención en este texto, se han agrupado los diferentes casos en tres grandes grupos más o menos homogéneos en función de los criterios y técnicas adoptados. Esta clasificación inicial no excluye que en una misma actuación puedan coexistir diferentes criterios y técnicas de intervención a tenor de un diverso estado de conservación o de otras necesidades.

El primero de estos tres grandes grupos, que denominamos intervenciones de recuperación de volúmenes, incluye aquellas donde se pretende recuperar las trazas y perfiles desaparecidos de una fortaleza o una muralla urbana mediante la restitución, más o menos sistemática, de su volumetría original. Estas actuaciones contribuyen a facilitar la legibilidad e identidad arquitectónica del conjunto así como los valores de significación colectiva del elemento donde se interviene, ya que permiten recuperar perfiles urbanos desapa- 

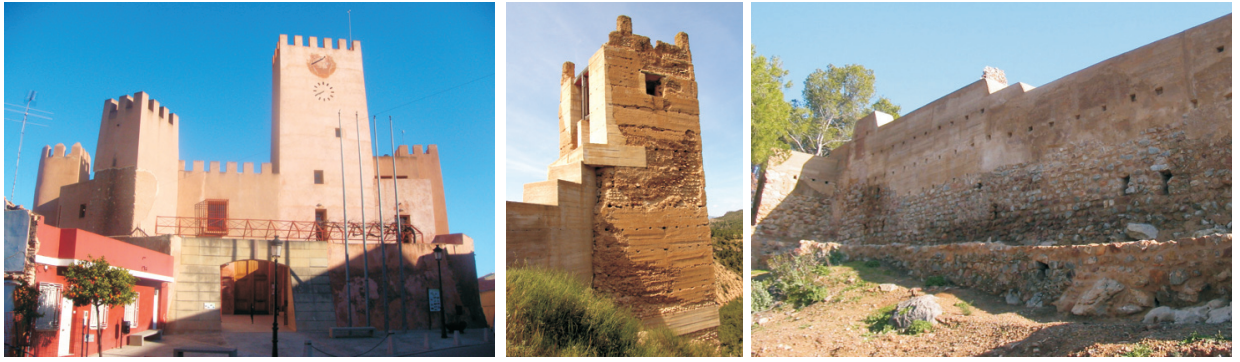

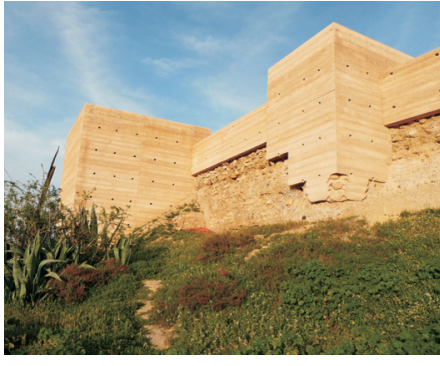

recidos o valores paisajísticos y territoriales. Las intervenciones de recuperación de volúmenes exigen una exhaustiva documentación arqueológica y documental que garantice la autenticidad de la intervención. Así mismo, en estas intervenciones, por el mismo proceso constructivo que se emplea, los elementos añadidos suelen ser claramente reconocibles, evitando el mimetismo con lo existente. En la práctica, no resulta fácil disponer de una información suficientemente documentada que permita garantizar o demostrar la autenticidad del elemento añadido, ya que la recuperación del perfil de una fortaleza exige tomar una serie de decisiones sobre la disposición, geometría y alzada de los lienzos originales que obliga, en muchos casos, a especular sobre su configuración original. Por otro lado, la importante aportación de material necesario en este tipo de intervenciones y el propio proceso constructivo de su ejecución y puesta en obra suponen llevar a cabo actuaciones que resultan difícilmente reversibles y que tienen como consecuencia directa la cubrición y, en muchos casos la destrucción, de valiosa información documental y arqueológica.

Las técnicas utilizadas en las intervenciones de recuperación de volúmenes en los ejemplos estudiados coinciden en utilizar el sistema del encofrado, enlazando directamente con el sistema tradicional de la tapia pero modificando o simplificando los mecanismos de apoyo, arriostramiento o fijación de los tableros. La principal dificultad radica en el encuentro con los perfiles deteriorados de la tapia original y su compatibilidad material, estructural y estética con los paramentos existentes, ya que en ocasiones la ejecución de la nueva tapia se realiza encofrando a una sola cara, lo que modifica sustancialmente el modelo original e introduce la necesidad de incorporar elementos de anclaje o llaves de fábrica para garantizar la estabilidad. El material utilizado oscila desde el máximo respeto a la materialidad existente, cuando se utiliza tierra estabilizada con cal aérea, hasta la incorporación de otros aglomerantes como la cal hidraúlica o el cemento con la intención de acelerar el proceso de fraguado de la masa. En los tapiales calicastrados, donde la costra era originalmente una mezcla de cal y arena, encontramos también adiciones de los aglomerantes descritos. En otros casos el volumen añadido se ha realizado con fábrica de hormigón de cemento mediante la técnica del encofrado, vertido y picado, sistema de cierta similitud en su puesta en obra y acabado superficial con el de la tapia tradicional, pero de escasa compatibilidad con los materiales originales.

Las primeras intervenciones de recuperación de volúmenes a gran escala se sitúan entre principios y mediados de la década de los ochenta del siglo XX, destacando los ejemplos de la restauración de la Muralla de Niebla (Huelva) realizada por Ismael Guarner González y la actuación en Toral de los Guzmanes (León) realizada por Eloy Algorri y Mariano Vázquez Espí. En ambos casos se realizaron estudios meticulosos de las tierras y los áridos utilizados para la construcción de las nuevas tapias, a las que se añadieron bajos contenidos de cal y cemento (15-16). Se recuperó la tecnica tradicional del encofrado de madera y apisonado de la tierra, lo que permitía que la textura del paramento presentara similitud con la de los originales (Figura 8). En el caso de la intervención en la muralla de Niebla (Figura 9), se intervino no sólo añadiendo volumen o cerrando lienzos sino también encofrando a una sola cara en los casos en que la tapia había perdido volumen lateralmente (17) (Figura 10). Se trata de una operación compleja y delicada por la dificultad de crear una conexión entre la preexistencia y la de nueva ejecución. Además, la variedad de los materiales presentes en las tapias del recinto amurallado de Niebla obligó a emplear técnicas similares para intentar obtener una semejanza de colores y texturas (17). A este periodo corresponde también la intervención del Castillo de Bétera (Valencia) Ilevada a cabo por Francisco Jurado Jiménez. En este caso, la masa de los muros se realizó con un "hormigón ciclópeo", una mezcla de tierras arcillosas, gravas, piedras de gran dimensión, cemento blanco y cemento gris, utilizando encofrado de tableros hidrófugos y revocando exteriormente los paramentos con mortero de cemento blanco, arena rojiza, arena blanca y colorante que confiere un aspecto homogéneo y novedoso (18) (Figura 11).
11. Vista general del Castillo de Bétera después de la intervención Valencia (fotografía: Mileto \& Vegas)

12. Torre del Castillo de Pliego después de la intervención (fotografía: F.J. López Martínez)

13. Un lienzo del Castell Vell después de la intervención (fotografía: F. Font)

14. Vista del Castillo de Nogalte en Puerto Lumbreras (Murcia) después de la intervención (fotografía: J.M. López Osorio) 
15. Vista de la Alcazaba de Almería después de la intervención (fotografía: J.M. López Osorio)

16. Detalle de la parte superior de la Torre de Albal (Valencia) después de la intervención (fotografía: Mileto \& Vegas)

7. Vista general de la Torre de Almussafes (Valencia) después de la intervención (fotografía: Mileto \& Vegas)

18. Fachada exterior del Cuarto Real de Santo Domingo en Granada después de la intervención (fotografía: J.M. López Osorio)
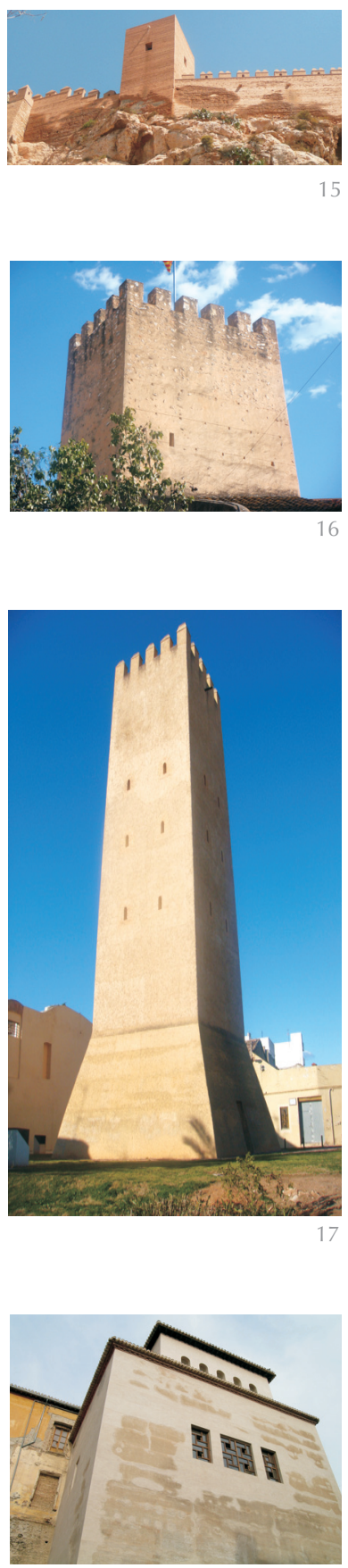

Otro grupo de actuaciones corresponde a las realizadas por Francisco Javier López Martínez en Murcia (19). Las restauraciones de los castillos de Mula y de Pliego (7) (Figura 12) muestran un riguroso conocimiento de la técnica tradicional de la tapia y su puesta en obra, llevando a cabo recuperaciones parciales de volumen con el objetivo de consolidar estructuralmente los restos de las fortalezas, elementos siempre claramente distinguibles de la preexistencia. A principos del siglo XXI podemos reseñar la intervencion realizada en el Castillo Alcazaba de Reina (Badajoz) (20-21), Ilevada a cabo por Gonzalo Díaz Recasens, donde se ha procedido a recuperar perfiles de torres y lienzos así como la restitución de los paramentos erosionados realizados según la técnica de la tapia tradicional, recuperando la modulación del encofrado original y realizando diversas pruebas de la mezcla de tierra, cal y arena, hasta alcanzar la máxima compatibilidad con la preexistencia. También reciente es la intervención realizada por J. Ignacio Gil-Mascarell y Fermín Font de recuperación de los lienzos de murallas del Castell Vell en Castellón (7) (Figura 13). En este caso con la tierra proveniente de las excavaciones arqueológicas enriquecida por un pequeño porcentaje de cal se ejecutaron las tapias calicastradas que se consideraron necesarias para consolidar las fábricas y para favorecer la lectura del conjunto. Para la costra se empleó un mortero de cal y grava enriquecido con una mínima cantidad de cemento blanco. Finalmente hacemos referecia a la intervención realizada en el Castillo de Nogalte (Puerto Lumbreras, Murcia) Ilevada a cabo por los arquitectos José Antonio Sánchez Morales y Carlos Jurado Fernández, en la que se realizan restituciones volumétricas de hormigón de cal pigmentado y encofrado con tableros de madera que manifesta huecos regulares simulando los mechinales de las agujas del sistema original (22-23) (Figura 14).

Un segundo grupo de intervenciones se puede identificar en las obras de reposición de la superficie de la tapia. Se trata normalmente de intervenciones dirigidas a proteger la superficie y la masa de la tapia erosionada por el paso del tiempo y los agentes atmosféricos generando una nueva superficie de enlucido. Además de la necesaria protección de las fábricas, existe un criterio de recuperación del decoro y la imagen unitaria como puesta en valor de la propia arquitectura y recuperación de una contundencia formal y volumétrica, asumiendo la necesaria renovación de las denominadas "superficies de sacrificio". Entre las posibles opciones se pueden identificar dos diferentes tendencias: por un lado, la conservación de los restos de la superficie antigua bien conservada y a la reintegración de las partes erosionadas con un nuevo estrato de acabado nuevo; por otro lado, una intervención más unitaria de sustitución o recubrimiento total de la superficie que conlleva un importante cambio de imagen que, además, en ocasiones puede originar una pérdida de información constructiva (improntas de los elementos del tapial como tablas, barzones, clavos, etc.) y de las huellas de la historia del edificio y de su uso (por ejemplo: la impronta de dibujos arquitectónicos en la tapia recién ejecutada, grafitis posteriores, revestimientos, capas de protección, fajas, despieces fingidos, etc.).

En este grupo de intervenciones, se puede incluir la realizada a principios de la década de los ochenta del siglo XX en el muro meridional de la Alcazaba de Almería. Una actuación Ilevada a cabo por Roberto Puig Álvarez donde, además de proceder a la restitución de volúmenes en torres y lienzos, se ejecutaron también reposiciones de paramentos parcialmente erosionados. El material utilizado fue un hormigón de tierra rojiza, grava, cal y cemento encofrado exteriormente para manifestar las improntas de la tapia. Esta actuación tuvo como consecuencia la aparición de grandes manchas de humedad en los lienzos que todavía permanecen (Figura 15).

En este mismo grupo podríamos situar también las intervenciones realizadas en algunas torres vigía de la provincia de Valencia. Se trata de torres destinadas al control y defensa del territorio, construidas entre el siglo XII y el XIII con tapia de tierra mejorada según los casos con cal, piedras, grava, etc. según los materiales disponibles en el mismo lugar (24). Algunas de estas torres han tenido importantes intervenciones donde, en aras a la conservacion de propia la fábrica, a la necesidad de paliar los fenómenos de degradación y a solventar la erosión de la capa protectora externa de la tapia, se ha realizado un nuevo revestimiento de las fachadas exteriores. Es el caso de la torre de Albal (Figura 16), restaurada como museo etnológico y completamente enlucida a principios de los años noventa en tres de sus cuatro fachadas con un estrato opaco de mortero que simula las huellas del tapial a través de unos agujeros rítmicos (simulacro de las agujas) y unas líneas horizontales modulares (simulacro de las juntas entre tapias). También en esta línea se debe entender la intervención llevada a cabo en 1995 por Ángel Esteve Garcerán y Santiago López Alonso (24) en la torre Racef en Almussafes donde aunque no se reconstruyera ninguna parte de su volumen se recubrieron la torre y su basamento ataludado con un enlucido continuo independiente de las posibles huellas contructivas de la superficie original (Figura 17). 
Otro ejemplo de sustitución de superficie, en este caso parcial y realizado con criterios de restauración y reintegración del existente, se puede encontrar en la intervención realizada en el año 2001 en el Cuarto Real de Santo Domingo de Granada, llevada a cabo por los arquitectos Antonio Almagro y Antonio Orihuela. La pérdida parcial de la costra en algunos sectores del paramento de la tapia calicastrada se reintegró mediante un mortero de cal enrasado con la superficie y con una textura similar a la conservada (Figura 18). Para mejorar las condiciones de adherencia se colocaron barras de madera de pequeño diámetro ancladas al muro de tapia a las que se anudó una sogueta de esparto que actuaba como armadura interior del nuevo revestimiento. La primera capa de éste se realizó con un mortero de cal y yeso con el objetivo de mejorar su adherencia.

Diverso por la técnica constructiva de partida pero similar a nivel de criterio de actuación es el caso de muchas intervenciones realizadas en tapias encadenadas con machones y verdugadas de ladrillo o piedra y cajones de tapia de tierra, cajones que pierden progresivamente su superficie de acabado Ilegando en algunos casos a importantes niveles de erosión y de pérdida de material. Las intervenciones contemplan generalmente la reposición de la superficie de protección del cajón con un revestimiento de mortero que en algunos casos se enrasa integrando la laguna en el nivel de la superficie del machón y llega a tener una continuidad con el rejuntado de la fábrica de ladrillo. Ésta fue la solución adoptada en la restauración de las fachadas de la iglesia de San Juan de los Reyes en Granada realizada en el año 2007 en actuaciones de conservación y protección de las fábricas. Estas intervenciones tienen como objetivo principal el mantenimiento de la materialidad original de la tapia, aceptando determinados niveles de deterioro y poniendo en valor las actuales cualidades de forma, textura y color de las estructuras existentes. Este criterio de intervención supone también la conservación de la estratificación de los diferentes acontecimientos constructivos que ha sufrido la estructura, ya sean acciones en negativo como aperturas de huecos de paso, o acciones en positivo como intervenciones históricas de reparación, transformación o restauración que se consideren adecuadas. Las actuaciones concretas se limitan, normalmente, a la consolidación superficial de los perfiles erosionados y a la aplicación controlada de capas de protección, ya sean morteros o simples lechadas de cal, que garanticen el mantenimiento de los sectores más degradados. La recontextualización temporal de la estructura histórica, la conservación de las improntas del sistema constructivo original o, simplemente, las nuevas cualidades formales que presenta un muro de tapia parcialmente destruido pero cargado de autenticidad, se consideran elementos más expresivos, didácticos y densos desde el punto de vista documental que la recuperación de su estado originario.

Éste es el caso de uno de los sectores restaurados en la Cerca de Don Gonzalo del Albaicín de Granada (Figura 20) por Javier Gallego Roca y José Manuel López Osorio en el año 1998 (26), donde se Ilevaron a cabo trabajos de conservación material de los restos existentes, manteniendo el perfil erosionado con el objetivo de permitir la
19. Vista general de la Iglesia de San uan de los Reyes en Granada después de la intervención (fotografía: J.M. López Osorio

20. Vista general de la Cerca de Don Gonzalo en Granada después de la intervención (fotografía: Mileto \& Vegas)

21. Detalle del tratamiento de las agunas en la restauración de la Cerca de Don Gonzalo en Granada (fotografía: Mileto \& Vegas)

22. Vista general del Muro de Alafia del Castillo de Xivert (Castellón) después de la intervención (fotografía V. Hofbauerova
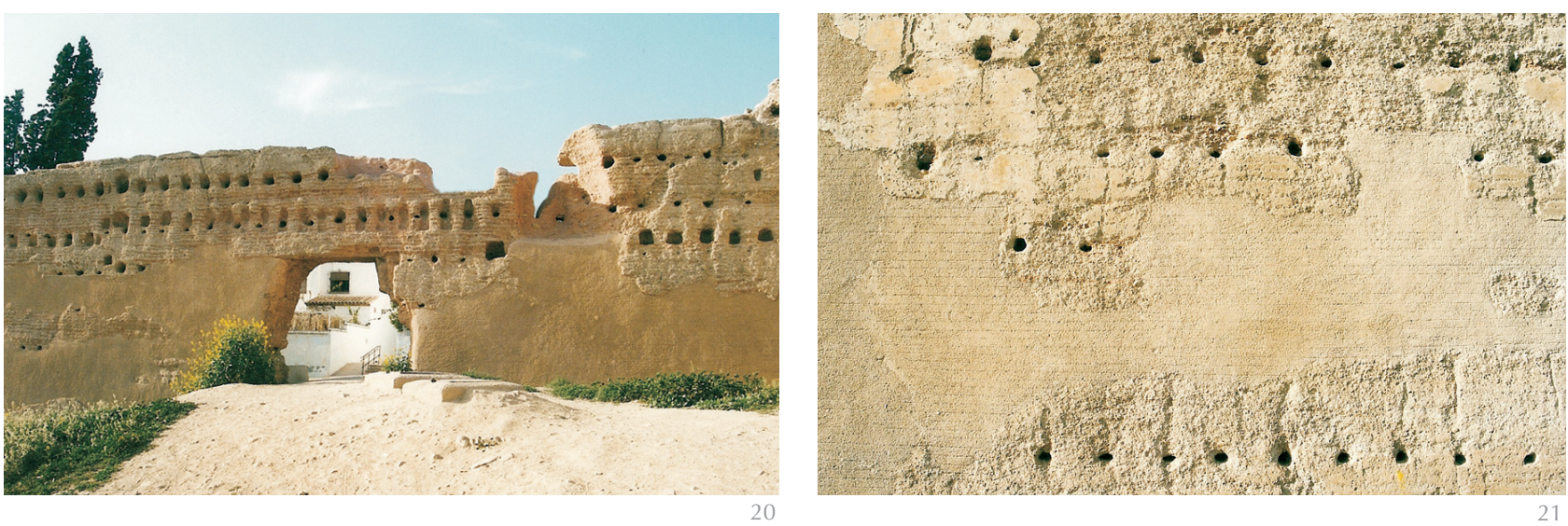

por Antonio Martín Muñoz y José Manuel López Osorio (Figura 19) (25). En otros casos, se recubre el cajón de tapia con una nueva superficie que sobresale respecto a la original de un espesor variable que crea un resalte del mismo respecto al resto de la fachada.

Por último, el tercer grupo de intervenciones de restauración de fábricas de tapia consiste permanencia y la contemplación de la ruina auténtica (27). La actuación consistió en la limpieza y consolidación superficial de la costra exterior con silicato de etilo, limitando la aportación de material a la aplicación de un mortero de cal con acabado rehundido y texturado que integra la laguna cubriendo los paramentos en aquellos sectores donde se ha producido la pérdida total de la costra

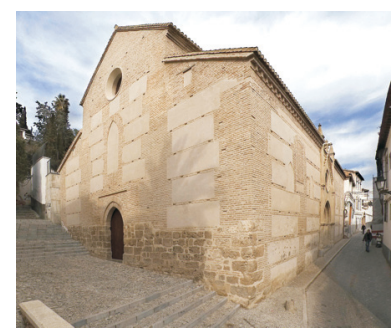


23. Vista de la torre Bofilla antes de la restauración, erigida sobre una plataforma elevada (fotografía: Mileto \& Vegas)

24. Fotoplanos de los cuatro alzados de la torre Bofilla antes de la restauración, con acotación de sus diversas tapias e indicación de la presencia de las fajas decorativas blancas, marcas de barzones impresas en la fábrica, lesiones y juntas de hormigonado de la tapia (fotoplanos: Global Alacant; elaboración: estudio Mileto \& Vegas) original (Figura 21). La desaparición de esta capa exterior había dejado sin protección la masa de tierra cruda existente en el interior del muro, siendo necesaria la ejecución de una nueva capa superficial para evitar la acción erosiva de los agentes antrópicos y atmosféricos.

Otro caso de conservación integral de la materialidad de la fábrica y protección de la misma es el de la restauración del muro de Alafia del Castillo de Xivert en Castellón, realizado por Vera Hofbauerova (28). El muro, construido en tapia calicastrada conservaba numerosas huellas del proceso contructivo y una inscripción con caracteres arábigos realizada en relieve en estuco de cal entre las bandas de despiece de sillería fingida, igualmente ejecutadas con estuco de cal de excelente calidad. La actuación consistió en la limpieza y consolidación del paramento decorado, y la realización de pequeñas reintegraciones de las oquedades con mampuestos y mortero de cal (Figura 22). La coronación del muro se protegió ejecutando una tapiada de tapia calicastrada hacia el interior del castillo, muy poco visible desde el exterior del mismo.

\section{LA RESTAURACIÓN DE LA TORRE BOFILLA EN BÉTERA (VALENCIA)}

La dirección de obra del proyecto de restauración de la torre Bofilla en Bétera, redactado por la arquitectura municipal Inma Buldú Gil, fue encargada a los arquitectos Camilla Mileto y Fernando Vegas López-Manzanares de la Universidad Politécnica de Valencia,

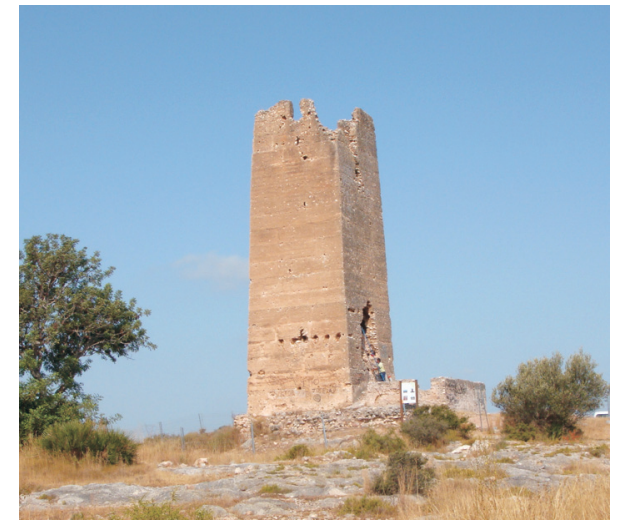

23

coautores de este texto. El análisis y estudio previo de la torre que a continuación se exponen constituyen un extracto del documento final de obra de la intervención de restauración sobre la misma, que debió reinterpretar y adaptar el proyecto inicial a tenor de los hallazgos de la obra.

\subsection{Historia}

La Torre Bofilla de Bétera (Valencia) es una torre de defensa de tapia erigida en época islámica junto con otra veintena de estructuras similares en un cinturón de unos 25 $\mathrm{km}$ en torno a la ciudad de Valencia (24). Se trata de torres ubicadas a una decena o más kilómetros de distancia de la costa sobre plataformas elevadas al pie de la red de caminos que antaño vertebraban el territorio (Figura 23). Entre estas torres se encuentran también la torre del castillo de Bétera, la torre de Albal y la torre Racef de Almussafes anteriormente
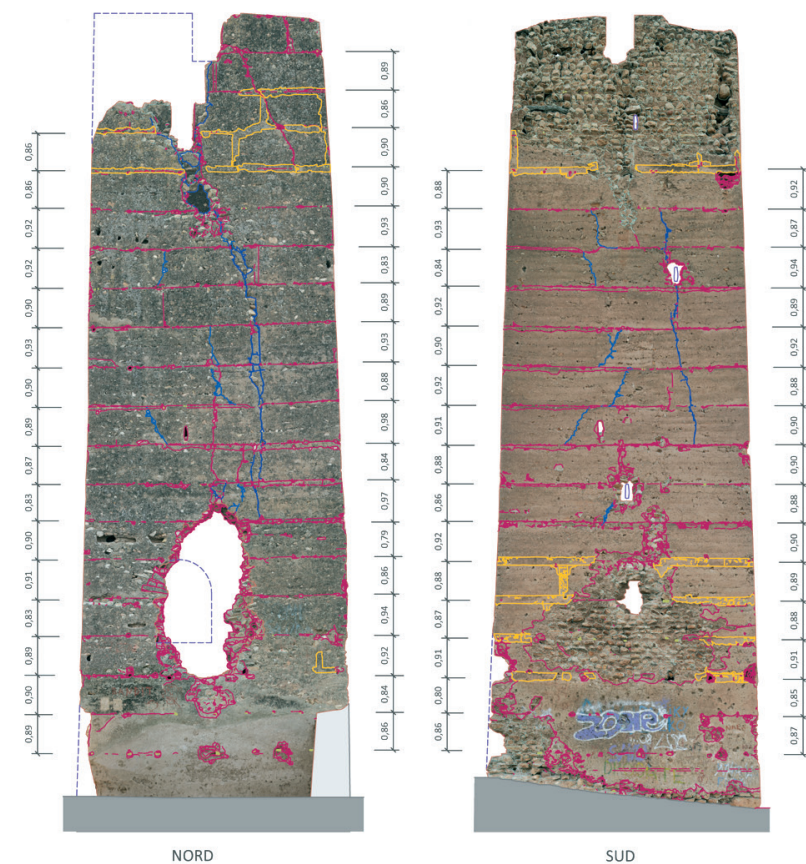

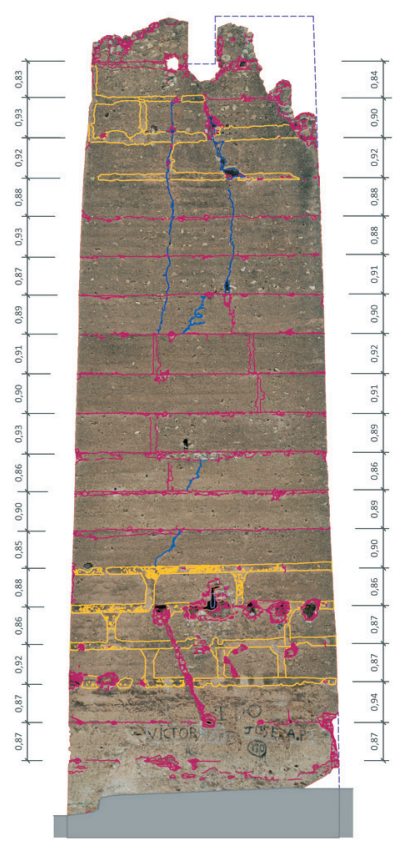

EST

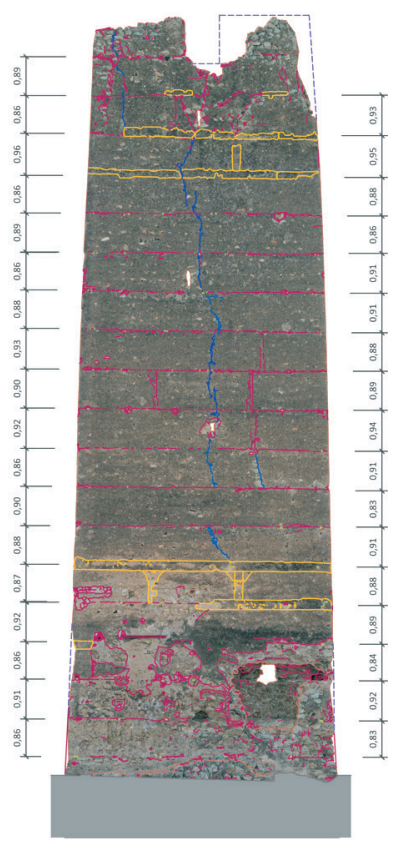

OEST 

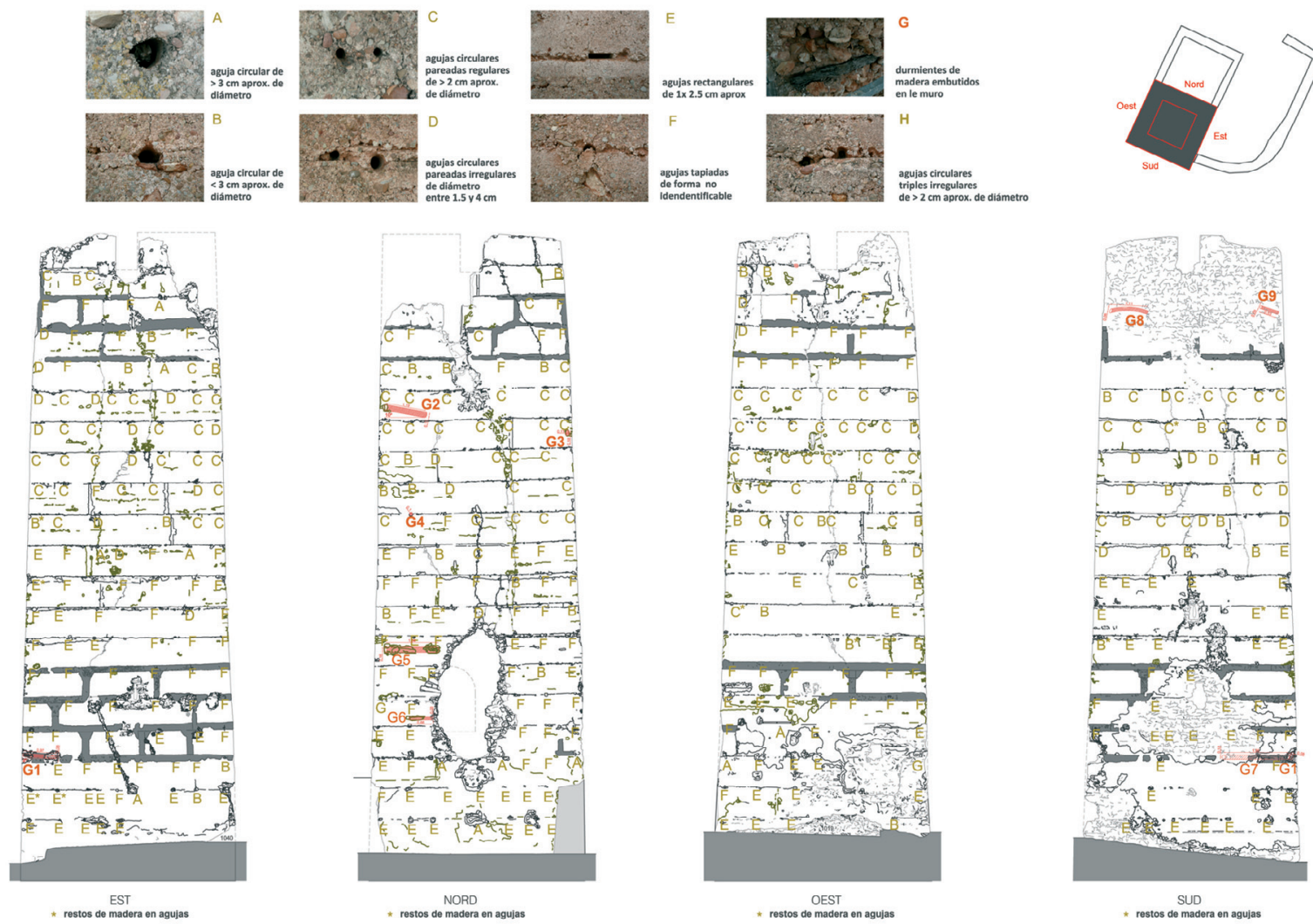

nombradas. La Torre Bofilla se ubica a unos $600 \mathrm{~m}$ del barranco de Carraixet, en una zona agrícola feraz de abundantes recursos hídricos, con los restos arqueológicos de la alquería árabe al pie de sus fábricas.

La alquería y la torre Bofilla nacieron probablemente a caballo entre los siglos XII y XIII en el contexto histórico de fortificación del territorio en torno a la ciudad de Valencia. La alquería fortificada islámica tuvo una vida de apenas unas décadas hasta la reconquista de Valencia en 1238 por parte de Jaime I el Conquistador que precisamente planteó como estrategia el hostigamiento y la rendición de las alquerías que rodeaban la ciudad, más que el ataque directo a la misma (29).

A partir de la conquista cristiana, la alquería aparece por primera vez en la documentación histórica a través de 17 noticias cronísticas y documentos, entre las cuales, el denominado Llibre del Repartiment y la Crónica de Jaume I. La torre fue donada por el monarca a la orden de Calatrava que ejerció su propiedad hasta mediados del siglo XIV, cuando la alquería se abandonó a causa de la carestía, las guerras contra Castilla y la peste negra (30). Al parecer los habitantes fueron absorbidos en el cercano núcleo de Bétera y siguieron cultivando las tierras de Bofilla como lugar privilegiado para la agricultura, pero sin ocupar sus construcciones.

\subsection{Descripción}

La torre responde a la misma tipología de construcción de otras torres islámicas similares del cinturón de la ciudad deValencia. Es de planta cuadrada con $6,15 \mathrm{~m}$ de lado que decrece en altura hasta la coronación con 5,20 m de lado, creando un perfil troncopiramidal. El espesor de los muros alcanza 1,20 m en la base de la torre y se adelgaza por el decrecido exterior y los resaltes internos de apoyo de los forjados hasta medir únicamente $56 \mathrm{~cm}$. Alcanza una altura total de algo más de 18 metros por el exterior en la esquina sureste, que equivale a 21 de módulos de tapia de dimensiones comprendidas entre 83 y $92 \mathrm{~cm}$ (Figura 24).

La torre mostraba restos de bandas decorativas blancas en la franja inferior y superior de alguno de sus frentes, a modo de despieces fingidos con grandes tendeles coronados con cálices, rayitas decorativas picoteadas en zigzag. Las bandas decorativas horizontales sellan las juntas entre tapias y los mechinales de las agujas correspondientes, de modo que poseen también una función protectora.

El acceso a la torre tenía lugar por una única puerta en un vano cubierto por un arco con dovelas de piedra, tanto en el exterior como en el interior. A pesar del expolio de las dovelas y el colapso posterior del entorno de este acceso, todavía se distinguen con claridad
25. Levantamiento de las cuatro fachadas de la torre Bofilla antes de la restauración con indicación de los tipos de agujas empleados en la construcción de la misma y el eventual hallazgo de durmientes y encadenados de rollizos de madera en el interior de la fábrica (dibujos: Global Alacant; elaboración: estudio Mileto \& Vegas) 


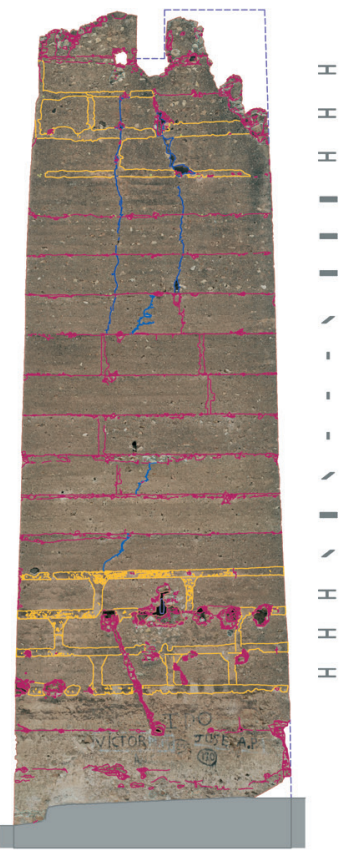

EST

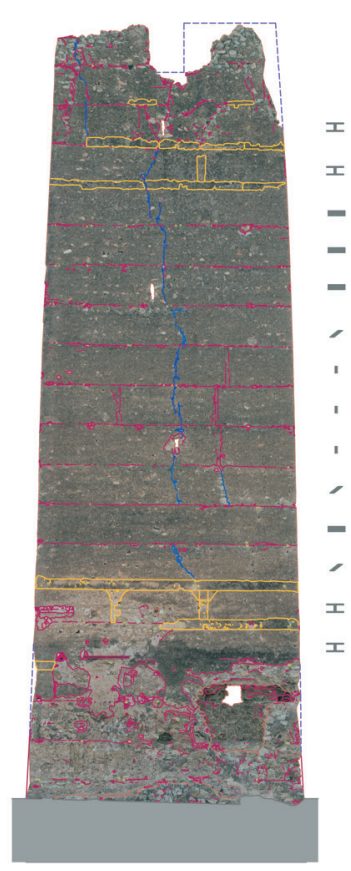

OEST
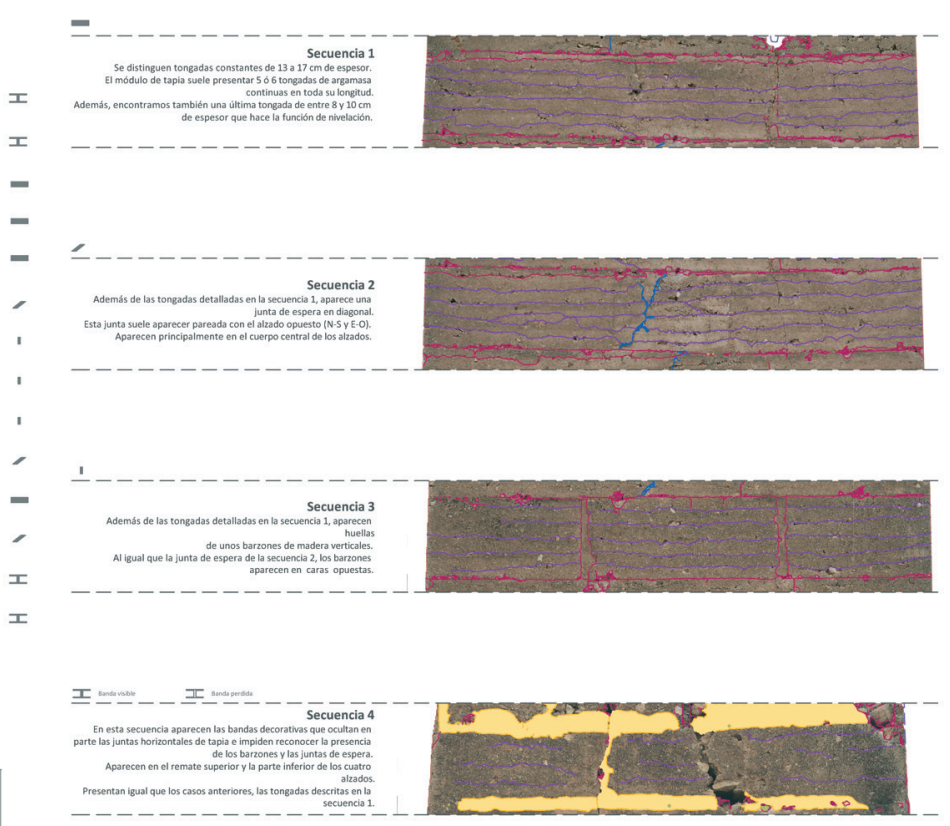

26

las dos mochetas que creaban un nicho para alojar la hoja de la puerta abierta y se adivina la presencia de la gorronera del quicio de la misma. Quedan huellas de los tres forjados y el paso de ronda que articulaban su interior. La modulación de la tapia marca la cadencia de los forjados, que se suceden cada cuatro tapias, desde el terreno exterior, hasta el tercer forjado. Por el contrario, la ligera estructura del paso de ronda se ubicaba a sólo tres tapias de altura del tercer forjado. Cada forjado poseía una pequeña saetera abocinada en cada frente. El paso de ronda daba acceso a las cuatro almenas semiderruidas en el centro de cada uno de los cuatro parapetos de coronación de la torre.

La materia prima empleada está formada por un $90 \%$ de tierra y áridos y un $10 \%$ de cal (31), con mampuestos de relleno en cada tongada de tapia de $15 \times 30 \mathrm{~cm}$ aproximadamente. Durante el proceso de apisonado, los áridos menores y la cal migraban hacia la superficie de los tablones creando una costra de protección que se ha conservado en gran medida hasta nuestros días y que es la responsable en último término de haber mantenido en vida y en pie durante los últimos 800 años una construcción en tierra con una envergadura equivalente a un edificio de viviendas de seis plantas de altura. Las bandas decorativas blancas están formadas por un fino mortero muy rico en cal, con proporción 1:1, perfectamente adherido a la tapia, probablemente, por su aplicación en fresco sobre la misma.

\subsection{Proceso constructivo}

En toda la envergadura de la torre aparecen de forma clara múltiples trazas de la construcción. La tapia, apoyada sobre roca en su base, fue construida en sus tres primeras hiladas encofrando únicamente por fuera y sirviéndose del terreno natural como encofrado interior. Las huellas de este procedimiento se pueden observar con todo detalle a raíz de las excavaciones realizadas en el interior de la
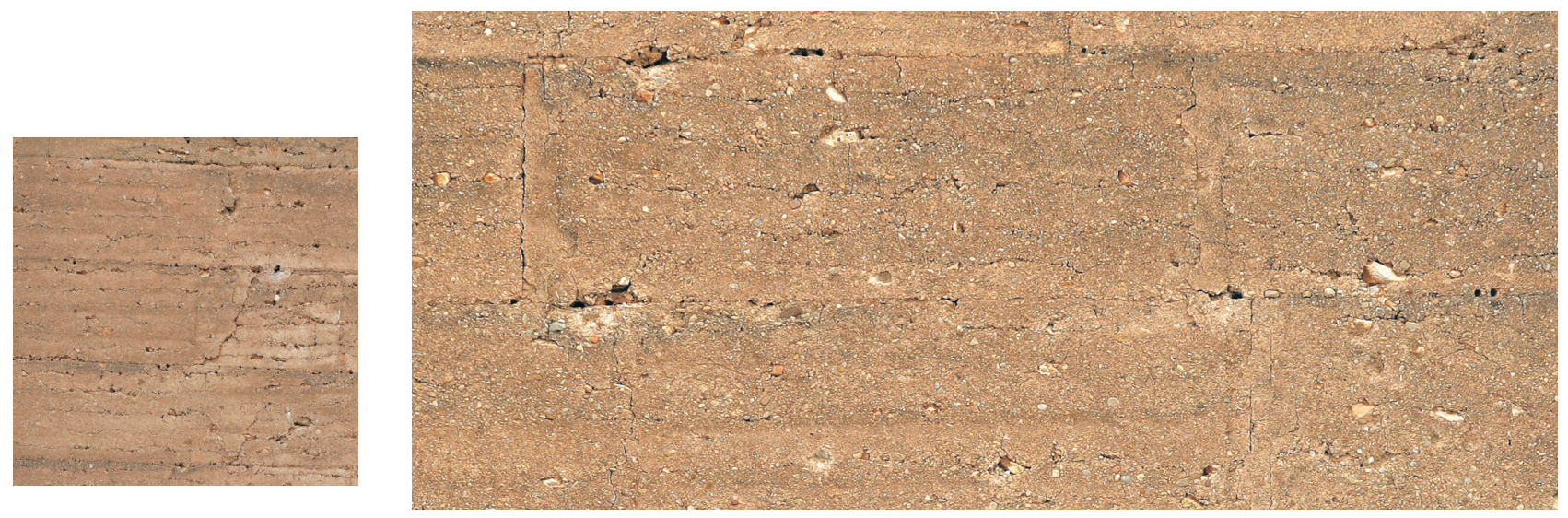
torre, merced al carácter plástico de la tapia en estado húmedo. A partir de ese punto, las tapias se fueron levantando con ayuda de encofrado exterior e interior, con sus agujas y codales, construyendo paulatinamente los forjados a medida que se alzaba la torre para facilitar la accesibilidad y el trabajo que predominantemente se dirigió desde el interior, para evitar la colocación de costosos andamios.

No obstante el sellado histórico de algunas de ellas, se ha detectado por ejemplo la presencia de varios tipos de agujas: circulares, rectangulares y pareadas, que se distribuyen por niveles de manera más o menos aleatoria por toda la altura del edificio (Figura 25). Las rectangulares responden a tablillas de madera perfectamente talladas, mientras que las circulares a ramas de menor o mayor diámetro, que dictan su presencia aislada cuando el tamaño es suficientemente grueso, o en grupos de dos o tres si las ramas son muy delgadas.

Merced a la degradación tanto interior como exterior de las fábricas, se ha desvelado también la existencia de toda una red de durmientes internos de madera embutidos dentro de la fábrica que han servido para zuncharla y encadenarla.

En algunos lugares todavía se detecta fácilmente la huella del encofrado de madera, que estaba formado por cinco tablas de 13 a $17 \mathrm{~cm}$ de altura. Estas tablas daban también la medida a las sucesivas tongadas de relleno y apisonamiento de la tapia. En primer lugar, se depositaban de manera ordenada los mampuestos y posteriormente, se vertía la tierra correspondiente a una tongada para su apisonado. Las tongadas describen una trayectoria ondulada suspendida entre los vértices extremos, que brindan a la fábrica un discreto carácter implosivo y precompresión hacia el interior. De hecho, cada uno de los módulos de tapia se remataba con una tongada estrecha de nivelación de 8 a $10 \mathrm{~cm}$, a veces, incluso con el recurso a un encofrado de tablas simples con nuevas agujas. La siguiente tapia comenzaba de nuevo con tongadas de trayectoria ondulada que se terminaban nivelando (Figura 26).

La tapia era continua en las esquinas, como suele suceder en las fortificaciones realizadas con tierra, aunque presenta eventualmente juntas de hormigonado con una inclinación aproximada de $65^{\circ}$ en el centro de los paramentos laterales. Para ello, las agujas cercanas a las esquinas se clavaban a unos durmientes especiales en forma diagonal dispuestos entre la esquina interior y la exterior. La torre presenta claros indicios de los encofrados con planta en forma de " $U$ " que se van girando alternados entre plantas, con marcas de barzones grabadas en negativo en la masa de la fábrica, rellenadas en fresco con la misma masa de la tapia en el exterior de la torre y dejadas vistas en el interior. Se trata probablemente de encofrados que provenían de la edificación doméstica en tapia, con barzones para hacer de barrera a las fronteras o cabeceros que delimitaban los módulos individuales de tapia, que se emplearon para edificar la torre con encofrado corrido sin modificaciones (Figura 27).

Existe una correspondencia clara en cada una de las tapias entre las caras de la torre con barzones grabados en negativo, enfrentadas entre sí, y las contiguas laterales a las mismas, que muestran las juntas de hormigonado (Figura 28). También es interesante observar en los planos como los encofrados con barzones van alternándose en el interior y el exterior de la torre para compensar la presión ejercida sobre las tablas y evitar que se combaran paulatinamente hacia una de sus caras.

La inclinación troncopiramidal de la cara de la tapia por el exterior venía marcada por las primeras tapias ya ejecutadas y los costales apoyados a las mismas a modo de regles, además de por los codales internos que impedían que la tapia se cerrase durante el proceso de compactado. El encofrado exterior iba reduciéndose paulatinamente a medida que se erigía la torre volando las alas del encofrado en cada esquina en forma de molinete. En el interior, las tapias son verticales y únicamente en el segundo y el tercer forjado se reducía el espesor del muro creando un quiebro que servía para apoyar las viguetas del forjado. Los mechinales de las viguetas del primer forjado muestran claramente que fueron excavados en el muro de tapia. Por último, la entrega de las viguetas del forjado del denominado paso de ronda también se verificaba mediante una roza continua en los muros.

\subsection{Forjados y escaleras}

En el interior cada uno de los niveles de los forjados conserva impresos en la tapia los mechinales de cada una de las viguetas e incluso se conservan en algunos casos restos completos de la sección de madera. Se trata de rollizos de unos 14-15 $\mathrm{cm}$ de diámetro que se disponían apretados entre sí, dejando un espacio similar entre los mismos. Cruzando el forjado en sentido perpendicular sosteniendo las viguetas, se disponía en cada forjado una viga parteluz en forma de rollizo de unos 20 $\mathrm{cm}$ de diámetro, cuyo mechinal ha quedado perfectamente impreso en la fábrica de la tapia. La disposición de la viga y viguetas de los forjados se iba cruzando en los forjados sucesivos. 
29. Derrumbe parcial de toda una frania vertical de tapia interior desde la brecha de acceso hasta la coronación (fotografía: Mileto \& Vegas)

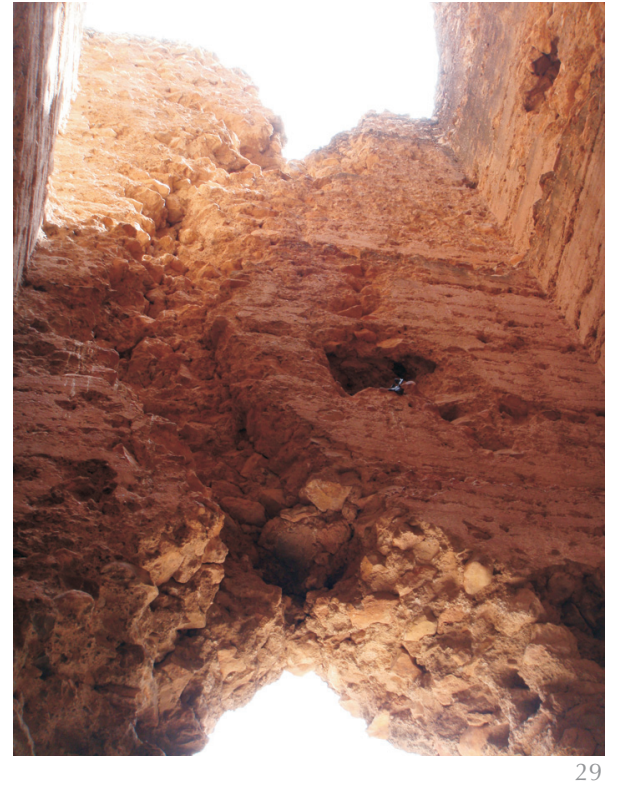

La posición cambiante de las escaleras se deduce muy claramente en los forjados primero, segundo y tercero de la ausencia de la hilera de mechinales apretados junto a la esquina en uno de los frentes de apoyo de los forjados. El hueco del paso de estas escaleras de mano se formaba con la ausencia de dos viguetas rollizo más los tres interticios entre ellos, esto es, 70-75 cm de anchura, por la mitad de la longitud del forjado marcada por la presencia de la viga central. Estas escaleras de mano iban cambiando de posición de forjado a forjado por el giro descrito en cada planta y por la imposibilidad de apoyar la escalera de mano sucesiva sobre el vacío de acceso de la inferior. Dada la modulación permanente de cuatro tapias en todos los forjados salvo el paso de ronda, es muy probable que la torre empleara una única escalera de mano para todos los niveles, que se iba desplazando para acceder al sucesivo, una garantía añadida al carácter defensivo de la misma.

El tercer forjado ofrecía un desnivel entre los apoyos marcados por las huellas de los mechinales de unos $10 \mathrm{~cm}$ entre los muros de apoyo hacia el frente oriental donde se ubicaba la perforación de desagüe de la cubierta. Por encima de este tercer forjado, se ubicaba otro nivel, el denominado paso de ronda, de cuya existencia existían las improntas de los mechinales de dos vigas en dirección Este-Oeste recibidas en su día a ambos lados de la almena central, y de una pequeña roza continua en los frentes Norte y Sur que indicaba la entrega de un forjado ligero forjado por muchas ramas. El paso de ronda perimetral al muro poseía un hueco central entre las vigas por donde se accedía por medio de una escalera de mano. La lluvia caía a través del hueco central a la terraza del forjado tercero donde se expulsaba a través de una gárgola de madera.

\subsection{Estado de conservación}

La torre Bofilla había llegado al umbral del siglo XXI en un estado de conservación muy aceptable considerando su antigüedad, excepción hecha de las zonas que habían sido objeto de agresiones antrópicas. Por ejemplo, las dovelas de los dos arcos, interior y exterior, que cubrían el vano de entrada habían sido expoliadas en el pasado, quizás para venderlas a un coleccionista o aprovecharlas en otra construcción. A pesar de la existencia de un dintel continuo superior formado por cuatro troncos de madera insertados en origen durante la construcción de la torre, esta sustracción había motivado el derrumbe parcial de toda una franja vertical de tapia interior hasta la coronación y la aparición por el exterior de una lesión vertical en coherencia con la debilidad generada por el derrumbe (Figura 29).

Por otra parte, la esquina suroeste había sido excavada paulatinamente para ofrecer un acceso alternativo al interior de la torre y aparecía completamente descarnada con un boquete alternativo de entrada. De la misma manera, y en este caso de forma natural, se había perdido masa de tapia en algunos puntos dejando a la vista los durmientes de madera. El frente sur presentaba dos zonas con importante pérdida de costra, en la parte inferior y en la superior, probablemene por la afección de la intemperie (Figura 30). Asimismo, se habían desconfigurado algunas aspilleras de la torre por la desaparición de sus dinteles de madera y losas, así como la erosión de sus jambas.

Los merlones del muro de coronación en la parte superior de la torre, esto es, allí donde la tapia es más delgada y está más expuesta a la intemperie ofrecían un estado semiderruido o frágil. Los cuatro frentes de la torre aparecían sucios o llenos de líquenes, particularmente los frentes norte y oeste. Además, existían otras pequeñas afecciones en la tapia, como la existencia de garras, grapas, soportes de antiguos tendidos eléctricos, impactos de bala, etc.

Las bandas decorativas se habían perdido o desprendido en algunas zonas, habían sido laceradas por la presencia de forjados adosados al exterior en otras y no existían inexplicablemente en algunos frentes, de manera que habían perdido su dimensión territorial de identificación de la torre en su entorno.

\subsection{Criterios de restauración}

La restauración de una torre casi milenaria $y$, en particular, de una construcción en tierra que lleva impresas en su superficie 
las trazas de su proceso constructivo y su configuración, hasta el punto que ha sido posible una interpretación muy completa de su antigua disposición a través de las mismas, precisamente por el carácter plástico de su materia prima, conlleva un grave peligro de desaparición de todas estas trazas. Además, gran parte del carácter de la torre y de su valor de antigüedad va ligado a la degradacion, erosión y abrasión de las superficies de la tapia. Pero esta afección de las superficies debe ponderarse y valorarse adecuadamente porque puede ir en contra de la propia supervivencia de la torre.

Singularmente, el municipio de Bétera posee dos torres islámicas del mismo tipo: la torre del castillo de Bétera, actualmente ubicado en el núcleo de la población, y la torre Bofilla a unos $3 \mathrm{~km}$ de distancia del mismo. La torre del castillo de Bétera, nombrada anteriormente, fue restaurada en los años ochenta del siglo XX con renovación completa de sus superficies a través del revoco generalizado de sus fachadas. Con ocasión de la restauración de la torre Bofilla, el alcalde indicó a los arquitectos que firman este artículo que la población no deseaba una restauración similar a la torre del castillo y deseaba conservar para sí en este caso el aspecto antiguo de las fábricas de tapia de la torre Bofilla, reparándola y mitigando su degradación, pero conservando su pátina y el potencial narrativo de las trazas impresas sobre la tierra de la tapia.

Por esta razón y en perfecta sintonía con los deseos de la población, se planteó la limpieza generalizada de todas las fachadas, siempre con un cepillado manual que no hiriera las superficies y que se detuviera antes de lacerar la pátina; la reparación estructural de todas las zonas necesitadas, como la esquina suroeste y el acceso con toda la franja de tapia interna desgajada en su vertical; el resarcido de las diversas lagunas de mayor o menor superficie del interior y el exterior de las fábricas; el rejuntado selectivo y estrictamente necesario de las zonas descarnadas del frente meridional, sin pretensión de devolver la costra perdida; la reconstrucción de la esquina noreste de la coronación desaparecida como medio de recuperar el perfil perdido de la esquina y atar los frentes oriental y septentrional que se encontraban sueltos; y la inserción de nuevos forjados y escaleras siguiendo escrupulosamente las trazas de los mechinales existentes en el interior de la torre, sin incidir en la fábrica.

\subsection{Restauración}

Todas estas operaciones que se han Ilevado a cabo en la restauración de la torre Bofilla se han puesto en obra con las modalidades

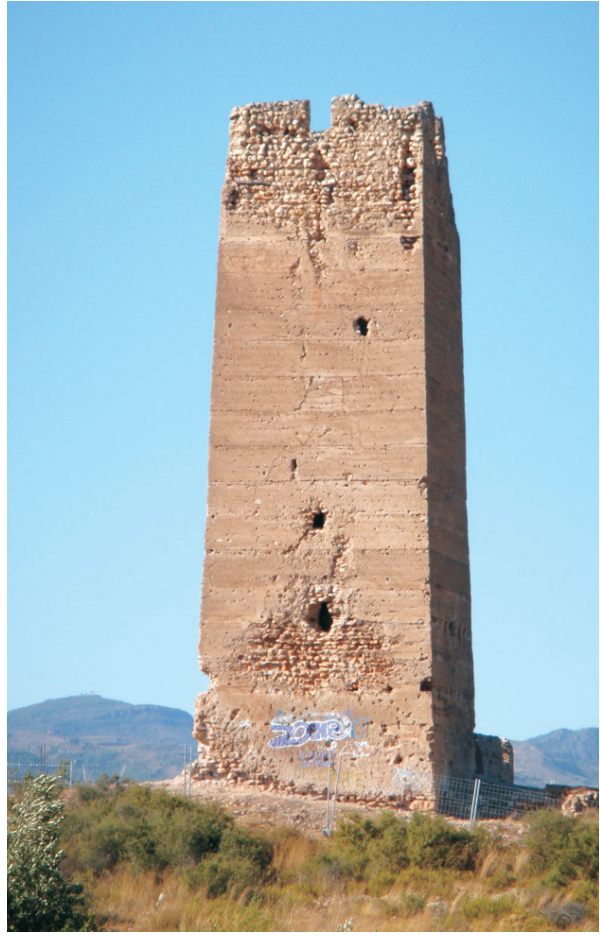

30. Vista de la fachada sur de la torre Bofilla antes de la restauración con presencia de dos zonas con pérdida de costra ubicadas en la parte inferior y superior (fotografía: Mileto \& Vegas)

31. Reintegración de laguna en la tapia ligeramente rehundida respecto a la costra original, con cepillado final del mortero y absorción de la cal superficial con esponja para conseguir una textura adecuada y patinado final (fotografía: Mileto \& Vegas)

de ejecución y acabado más inocuas para la fábrica histórica, desde un punto de vista de la compatiblidad estructural, física, química y estética o visual. Por ello, las reparaciones estructurales y los resarcidos de lagunas de la tapia de tierra y cal han contemplado también su aspecto final y posibilidades de integración en el conjunto.

Previamente a realizar cualquier tipo de reintegración, se procedió a una limpieza generalizada de las fachadas mediante un delicado cepillado manual con ayuda de sales de amonio cuaternario como fungicida, que permitió la eliminación de los líquenes y vegetación superior que infestaban la superficie y fisuras de la fábrica. Esta limpieza no

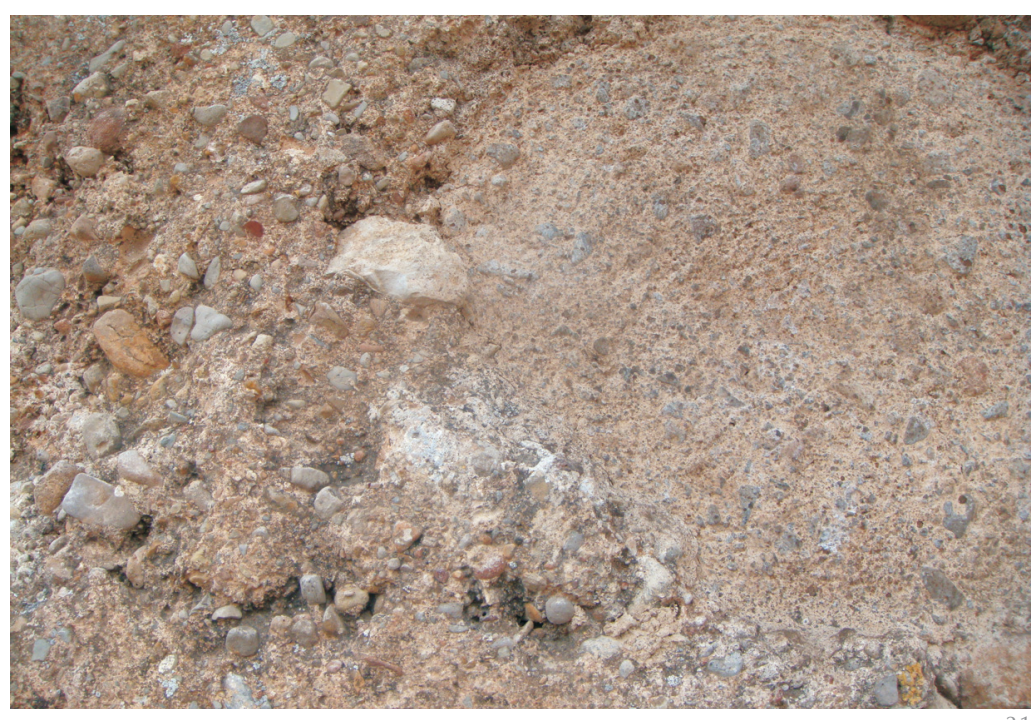




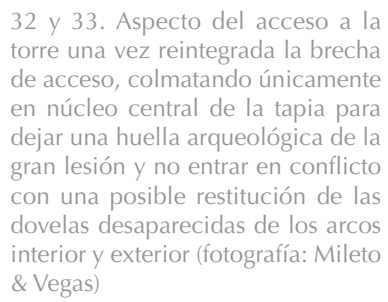

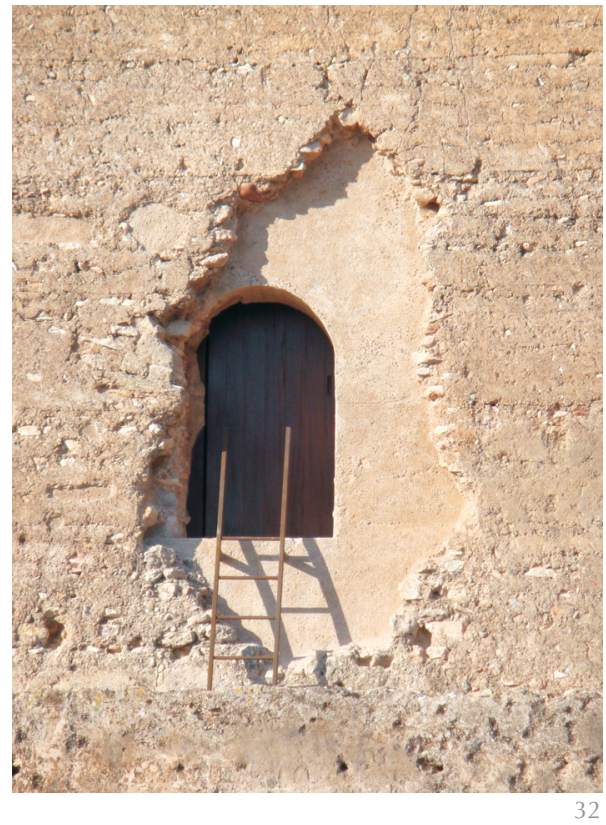

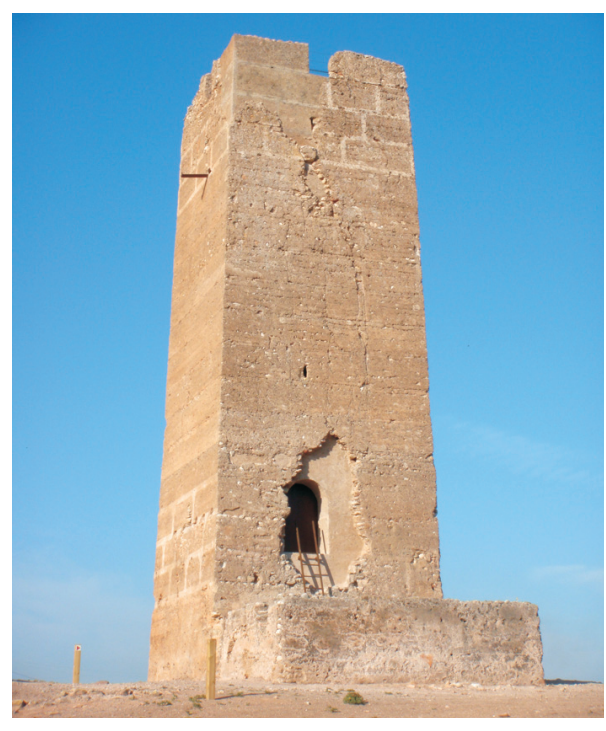

se llevó al punto de eliminar absolutamente todos los líquenes ni la pátina del tiempo, en particular en los frentes norte y oeste, donde una limpieza en profundidad habría erosionado la costra original de la tapia. En las zonas inferiores de la torre pintadas con grafitis, sin embargo, se debió aplicar un decapante específico para poder eliminar estas pinturas inoportunas. Una vez calibrado el grado de limpieza y ultimada la misma, esto es, una vez determinado el color y la vibración cromática final de las superficies de la torre, se pudo proceder a las reintegraciones de la tapia.

El resarcido de las lagunas laterales aisladas y la compleción de la franja de tapia interna desgajada sobre la vertical del acceso no se podían encofrar y compactar como en su día se construyó la tapia, por la dificultad y la falta de espacio de maniobra, aunque sí era posible sin embargo encofrar la esquina reconstruida en el ángulo noreste. Pero ni siquiera en el último caso se recurrió al encofrado para la reconstrucción porque la superficie resultante de la integración, con su aspecto liso, terso y recién construido, habría entrado en franca contradicción con la antigüedad del resto de la torre, hasta el punto que habría atraído más la atención el nuevo añadido por su color y su textura que el antiguo edificio. En términos gestálticos, habríamos invertido lo que debería ser fondo (los añadidos actuales) en el conjunto de la figura (la torre), que en ese caso pasaría a ser figura (los añadidos) destacada sobre el fondo (la torre). Además, esta superficie reintegrada se habría colocado en el plano exterior de costra de la tapia original, cuando en el fondo se deseaba una reintegración ligeramente rehundida, entonada y texturada respecto a este plano de acabado original (Figura 31).

Por este motivo, se han operado las reintegraciones aparejando los mismos mampuestos caídos de la torre que se encontraban a sus pies con una disposición parecida a la que presentan en el interior de la tapia con ayuda de mortero de cal hidráulica natural NHL 5 y enluciendo esta fábrica con el mismo mortero en proporción 1:3. El árido empleado en la elaboración ha sido una mezcla de aglomerado comercial con guijarros locales recogidos a pie de la torre, para conseguir que el aspecto del acabado final se integrara en el lugar a través de la textura y el color de los áridos locales. No se ha recurrido al empleo de la misma proporción de tierra y cal que existe en la tapia original porque su solidez, compacidad y resistencia estructural no depende tanto de esta mezcla concreta, sino sobre todo de una puesta en obra por apisonamiento concienzudo de tongadas característico de la tapia, que no era posible reproducir de ningún modo en la reintegración de las lagunas.

El plano de acabado de este grueso enlucido sobre la fábrica de mampostería que rellena las lagunas se ha dejado ligeramente rehundido respecto de la costra de la tapia original adyacente. Este rehundido queda bien patente en la esquina noreste reconstruida, donde la alternativa de empleo de un encofrado habría obligado a un cepillado intensivo para alcanzar el plano rehundido con la consecuente debilitación de la costra de la nueva tapia. En el acceso a la torre, se ha dejado una huella arqueológica de la gran brecha que hería este frente reintegrando únicamente el núcleo central de la tapia para evitar entrar en conflicto con una posible restitución de las dovelas desaparecidas de los arcos interior y exterior, que habrían generado un gran impacto en su imagen (Figura 32). 
Posteriormente, y a medio fraguar la mezcla, se ha procedido a cepillar manualmente la superficie de acabado para sacar a relucir el aglomerante del mortero y conseguir una cierta textura que ayudara a una integración de las lagunas en su contexto ligeramente erosionado de la tapia original. Este mortero de cal hidráulica que se ha tintado en masa con adición de pigmentos naturales para entonarlo con las zonas más claras de la tapia original adyacente, se patinó posteriormente con un estarcido de tierras naturales aglomeradas con cal aérea con la voluntad de armonizar la laguna reintegrada con la textura y la vibración de cada contexto de la tapia histórica. En las zonas que un día lucieron grafitis que habían clareado por la agresividad del decapante empleado en su limpieza, se empleó como aglomerante de las tierras naturales silicato potásico por su mayor opacidad y capacidad cubriente.

Así, las lagunas reintegradas en la torre se han conseguido armonizar dentro de su contexto construido en color y textura, al tiempo que su ubicación en un plano más o menos rehundido respecto a la costra original de la tapia permite distinguir perfectamente los añadidos (Figura 33). De la misma manera que en una pintura restaurada con la técnica del rigattino, quien desea solazarse en la contemplación general de la torre no encuentra interferencias o conflictos visuales en su complexión global, mientras que el erudito, el técnico o cualquier persona interesada puede distinguir perfectamente aquellas zonas o lagunas que han sido objeto de reintegración.

En las zonas descarnadas superior e inferior del frente sur, se ha procedido al rejuntado selectivo con mortero de cal hidráulica natural de aquellos mampuestos que ofrecían inestabilidad y aquellos lugares donde la Iluvia podía embalsarse. Este rejuntado selectivo, que se ha limitado a lo mínimo indispensable, se ha cepillado posteriormente y se ha patinado para garantizar una correcta armonización con su entorno construido inmediato. Se ha conservado de este modo el carácter debido a la erosión debida al paso del tiempo y a la exposición a la intemperie, pero se ha mitigado la degradación, en primer lugar, para garantizar la supervivencia del muro, objetivo primoridal de cualquier restauración, y en segundo lugar, para devolver un cierto decoro y seguridad visual a la fábrica que no mermase sin embargo el valor de antigüedad y el carácter venerable de la torre.

Por último, se han insertado nuevos forjados en el interior de la torre que no sólo sirven para arriostrar y anclar los frentes de tapia entre sí, sino también para permitir un mantenimiento consuetudinario de la misma y una eventual visita especializada a sus fábricas, vista la incompatiblidad del cumplimiento de la normativa actual, basada en garantizar la seguridad del acceso y la evacuación, con la restitución arqueológica de los forjados y escaleras originales de la torre, concebida por el contrario para impedir o dificultar el acceso a la misma. Para ello, se han empleado vigas y viguetas, de $12 \times 18 \mathrm{~cm}$ y $9 \times 12 \mathrm{~cm}$ respectivamente, que se han insertado en los mechinales que ya existían sobre la fábrica sin incidir en la misma y se ha pavimentado con un entablado machihembrado macizo de 5 $\mathrm{cm}$ de espesor recogido por un encintado metálico perimetral retirado de las fábricas para evitar incidir en ellas. Las vigas y viguetas son laminadas en vertical de tipo bilama para controlar su deformación y torsión posterior sin perder la naturalidad del aspecto de las vigas naturales. Las escaleras de mano se han realizado en metal y se han entregado en obra siguiendo igualmente las huellas de su posición e inclinación originales. El interior reconstruido no ha pretendido tanto imitar los forjados originales que estaban construidos con rollizos apenas desbastados y entablados con una capa de tierra y cal como pavimento superior, sino restituir la morfología de los mismos siguiendo las improntas de la fábrica, recurriendo a maderas y escuadrías accesibles comercialmente en la actualidad.

\section{CONCLUSIÓN}

La restauración de la arquitectura de tapia, en este texto representada por arquitecturas monumentales, constituye un reto importante para la disciplina de la restauración. La técnica constructiva del tapial y el material tierra presente en casi la totalidad de estas arquitecturas suponen unos conocimientos específicos tanto a nivel de proceso de construcción como a nivel de técnicas de intervención debido a las peculiaridades del propio material, a su puesta en obra y a los fenómenos de su degradación. Frente al diverso estado de conservación de estas estructuras y a las aspiraciones de restauración y puesta en valor de las mismas, se abre un abanico de opciones de intervención tanto a nivel de criterios como de técnicas a emplear. El reto que se plantea a los arquitectos consiste en conciliar en la medida de lo posible las necesidades derivadas de la degradación progresiva de estas estructuras, la peculiaridad del material y la técnica constructiva, por un lado, y las exigencias derivadas de los criterios de la disciplina como la conservación de la autenticidad histórico-cultural, la autenticidad material y constructiva, la reversibilidad, la distinguibilidad, la compatibilidad y la durabilidad de la intervención, por otro lado, además de cumplir con los principios de la neutralidad y la mínima intervención necesaria en aras a la conservación del carácter del edificio.
Esta investigación se engarza en los estudios relacionados con el proyecto de investigación "La restauración de la arquitectura de tapia en la Península Ibérica. Criterios, técnicas, resultados y perspectivas" (ref. BIA201018921) por parte del Ministerio de Ciencia e Innovación durante el periodo 2011-2013. 


\section{BIBLIOGRAFÍA}

(1) AA.VV.: Terra Incognita. Préserver un Europe des Architectures de tierre, p. 22, Culture Lab Editions - Argumentum, Bruselas-Lisboa, 2008.

(2) López Martínez, F.J.: "Tapias y tapiales". Loggia - Arquitectura y Restauración, nº 8 (1999), pp. 7580.

(3) De Villanueva, J.: Arte de Albañilería, p. 25, Edición facsímil - COAG, Lugo, 2001 (1827).

(4) Warren, J.: Earthen Architecture: The conservation of brick and earth structures. p. X, ICOMOS International Committee on Earthen Architecture, 1999.

(5) Font, J.: "Églises en pisé mixte à Palencia". Mediterra 2009 - 1st Mediterranean Conference on Earth Architecture, (2009), pp. 58-59.

(6) Graciani, A.; Tabales, M.A.: "El tapial en el área sevillana. Avance cronotipológico estructural". Arqueología de la Arquitectura, n. 5 (2008), pp. 135-158.

(7) Font, F.; Hidalgo, P.: Arquitecturas de tapia. COAATC, Castellón, 2009.

(8) Espinar Moreno, A. L.; López Osorio, J. M.: Estudios previos para restauración del Baño Árabe de Zafra. Consejería de Cultura de la Junta de Andalucía, texto inédito, 2000.

(9) López Osorio, J.M.: Análisis constructivo de la tapia calicastrada en la muralla del Albaicín de Granada, texto inédito, 2008.

(10) De Hoz, J.; Maldonado, L.; Vela, F.: Diccionario de construcción tradicional: Tierra. ad vocem, Ed. Nerea, Madrid, 2003.

(11) De San Nicolás, F.L.: Arte e uso de architectura. p.61, 1663.

(12) Cristini, V.; Ruiz, J.R.: "Tapia valenciana: caratteristiche di muri in terra cruda rinforzati con mattoni". Mediterra 2009 - 1st Mediterranean Conference on Earth Architecture, (2009), pp. 285-294.

(13) Galarza, M.: "La tapia valenciana: una técnica constructiva poco conocida". Actas del Primer Congreso Nacional de Historia de la Construcción, (1996), pp. 211-215.

(14) Vegas, F.; Mileto, C.; Cristini, V.: "Reinforcement of rammed esrth constructions with gypsum in Aragon area, Spain". Mediterra 2009 - 1st Mediterranean Conference on Earth Architecture, (2009), pp. 99-108.

(15) Guarner, I.: "Muralla de Niebla, Huelva". Jornadas sobre restauración y conservación de monumentos, (1991), p. 145.

(16) Vázquez, M.; Algorri, E.: "Rehabilitación del Castillo de Toral de los Guzmanes, León". Jornadas sobre restauración y conservación de monumentos, (1991), p. 152

(17) Guarner, I.: "La restauración del recinto amurallado de Niebla". Informes de la Construcción, n³4445 (1982), p. 50-53.

(18) Jurado, F.: "Rehabilitación de la casa-castillo de Bétera, Valencia". Jornadas sobre restauración y conservación de monumentos, (1991), pp. 174-175.

(19) López Martínez, F.J.: Tapiería en fortificaciones medievales - región de Murcia. Universidad Poltécnica de Valencia, tesis doctoral inédita, 2003.

(20) Rocha, M.: "Consolidaçao das muralhas de tapia no Castelo de Reina". Terra em Seminário - IV Seminário Ibero-Americano de Construçao con Terra, (2005), p. 119.

(21) Rocha, M.: "Castelo de Reina". Houses and cities built with earth. Conservation, significance and urban quality, (2006), p. 62.

(22) Fernández, F.J.; Granados, J.; Hernández, I.M.; Martínez, J.A.: "Intervenciones en el Castillo de Nogalte y su entorno". XX Jornadas de Patrimonio Cultural de la Región de Murcia, (2009), pp. 175-177.

(23) Sánchez, J.A.; Mesa Del Castillo, M.: "Restauración del Castillo de Nogalte". Catálogos de arquitectura, n. 18 (2006), pp. 72-77.

(24) Rodríguez Navarro, P.: La torre árabe observatorio en tierras valencianas. Tipología arquitectónica. Tesis doctoral inédita. Universidad Politécnica de Valencia, 2008.

(25) Martín, A.; López Osorio, J.M.: "Restauración de la iglesia mudéjar y alminar de San Juan de los Reyes de Granada". Boletín del Instituto Andaluz del Patrimonio Histórico, n. 62 (2007), pp. 86-107.

(26) Gallego Roca, F.J.: Restauración de la Muralla del Albayzín de Granada - Camino Viejo de San Antonio. Dirección General de Bienes Culturales - Junta de Andalucía, texto inédito, 1998.

(27) Gallego, F.J. (ed.): La ciudad y sus murallas. Conservación y restauración. p. 34, Universidad de Granada, Granada, 1996.

(28) Hofbauerova, V.; De Antonio, J.M.: "Consolidación y restauración del muro de Alafia. Castillo de Xivert (Castellón)". Loggia - Arquitectura y Restauración, n. 11 (2001), pp. 74-85

(29) Bazzana, A.; Guichard, P.: "Les tours de defénse de la huerta de Valence au XIII s". Mélanges de la Casa Velázquez, n. XIV (1978), pp. 73-106.

(30) López Elum, P.: La alquería islámica en Valencia. Estudio arqueológico de Bofilla, siglos XI a XIV. pp. 42-45, Valencia, 1994.

(31) Kröner, S.; Osete, L.; Domenech, M.T.: Informe analítico LMP 37_09. p. 12, IRP - UPV, documento inédito, 2009. 